\title{
Greater dyspnea is associated with lower health- related quality of life among European patients with COPD
}

This article was published in the following Dove Press journal:

International Journal of COPD

20 March 2017

Number of times this article has been viewed

\author{
Jean-Bernard Gruenberger' \\ Jeffrey Vietri ${ }^{2}$ \\ Dorothy L Keininger ${ }^{1}$ \\ Donald A Mahler ${ }^{3}$
}

'Health Economics and Outcomes Research, Novartis Pharma AG, Basel, Basel-Stadt, Switzerland; ${ }^{2}$ Health Outcomes Practice, Kantar Health, Horsham, PA, ${ }^{3}$ Geisel School of Medicine at Dartmouth, Hanover, $\mathrm{NH}$, USA

Correspondence: Jeffrey Vietri Health Outcomes Practice, Kantar Health, 700 Dresher Road, Horsham, PA 19044, USA

Tel +l 9088873535

Email jeffrey.vietri@kantarhealth.com
Objective: Dyspnea is a defining symptom in the classification and treatment of chronic obstructive pulmonary disease (COPD). However, the degree of variation in burden among symptomatic COPD patients and the possible correlates of burden remain unclear. This study was conducted to characterize patients in Europe currently being treated for COPD according to the level of dyspnea in terms of sociodemographics, health-related quality of life, work productivity impairment, and health care resource use assessed by patient reports.

Methods: Data were derived from the 5-EU 2013 National Health and Wellness Survey $(\mathrm{N}=62,000)$. Respondents aged $\geq 40$ years who reported currently using a prescription for COPD were grouped according to their level of dyspnea as per the Global Initiative for Chronic Obstructive Lung Disease guidelines and compared on health status (revised Short Form 36 [SF-36]v2), work impairment (Work Productivity and Activity Impairment questionnaire), and number of health care visits in the past 6 months using generalized linear models with appropriate distributions and link functions.

Results: Of the 768 respondents who met the inclusion criteria, 245 (32\%) were considered to have higher dyspnea (equivalent to modified Medical Research Council score $\geq 2$ ). Higher dyspnea was associated with decrements ranging from 3.9 to 8.2 points in all eight domains of the SF-36 health profile after adjustment for sociodemographics, general health characteristics, and length of COPD diagnosis; mental component summary scores and Short Form-6D health utility scores were lower by 3.5 and 0.06 points, respectively. Adjusted mean activity impairment ( $55 \%$ vs $37 \%, P<0.001)$ and number of emergency room visits $(0.61$ vs $0.40, P=0.030)$ were higher in patients with greater dyspnea.

Conclusion: Many European patients with COPD continue to experience dyspnea despite treatment and at levels associated with notable impairments in the patients' ability to function across a multitude of domains. These patients may benefit from more intense treatment of their symptoms.

Keywords: COPD, dyspnea, health-related quality of life, activity impairment, symptoms

\section{Introduction}

Patients with chronic obstructive pulmonary disease (COPD) experience significant overall symptom burden, comparable to that observed in patients diagnosed with cancer. ${ }^{1}$ This symptom burden can be associated with impairments in health-related quality of life (HRQoL), ${ }^{2-4}$ impaired functioning, ${ }^{5,6}$ and higher direct ${ }^{7}$ and indirect costs. ${ }^{7-9}$ COPD treatments have shown effectiveness in reducing breathlessness and improving HRQoL. ${ }^{10-17}$ However, some patients continue to experience dyspnea despite treatment. ${ }^{18,19}$ Moreover, this is critical given that recent studies suggest that 
the COPD-associated burden is increasing globally and costs are increasing in tandem..$^{20,21}$ The European Lung White Book estimates that, COPD is responsible for 150,000 deaths and 1,691,000 disability-adjusted life years lost in Europe, thus reinforcing the tremendous burden that COPD exerts on society at large. ${ }^{22}$ In Europe, COPD is estimated to be responsible for $€ 48.4$ billion in health care costs and lost productivity each year, including an estimated $€ 25.1$ billion in indirect costs alone. ${ }^{22}$

Of all the symptoms of COPD, dyspnea is the most dominant and defining one. ${ }^{1}$ Dyspnea is defined as a subjective experience of breathing discomfort that consists of qualitatively distinct sensations that vary in intensity. ${ }^{23}$ The discomfort associated with dyspnea has been shown to affect HRQoL and health status. ${ }^{24-27}$ In recognition of the prominent role of dyspnea in the assessment and management of COPD, the Global Initiative for Chronic Obstructive Lung Disease (GOLD) strategy recommends the use of patient-reported severity of dyspnea as part of the patient classification system. The international group recommends the routine use of screening measures, such as the COPD Assessment Test ${ }^{28}$ or the modified Medical Research Council (mMRC) ${ }^{29}$ scale, to assess dyspnea among patients. Such assessments require individuals to report the degree of activity that results in breathlessness (eg, walking up a flight of stairs) and correlate well with health status ${ }^{30}$ and longer assessment measures. ${ }^{31}$

Despite the importance of self-reported dyspnea in the classification and treatment of COPD, the degree of variation in burden in patients with symptomatic COPD and the possible correlates of burden remain unclear. This is particularly true on an international level, whereby there exists a paucity of large-scale representative studies. The aim of this study was to characterize patients in Europe currently being treated for COPD according to their level of dyspnea in terms of sociodemographics, HRQoL, work productivity impairment, and health care resource use assessed by patient reports.

\section{Methods}

\section{Study population}

Data were derived from the 5-EU 2013 National Health and Wellness Survey (NHWS; N=62,000). The survey sample was representative of adults in France, Germany, Italy, Spain, and the UK, in terms of age and gender; all the data were self-reported. The protocol for the NHWS was reviewed and approved by Essex Institutional Review Board (Lebanon, NJ, USA; protocol number KH-NHES-EU13), and all respondents provided informed consent. In the current study, respondents aged $\geq 40$ years and currently receiving prescription medication for COPD, emphysema, and/or chronic bronchitis (hereafter referred to as COPD) were included. Patients with asthma were excluded from the selected group to ensure that dyspnea was a symptom of COPD in the respondents rather than attributable to asthma.

Participants were categorized into lower and higher dyspnea groups using an item based on the mMRC scale and the GOLD categorization ( $\mathrm{mMRC}$ levels $0-1$ vs $\geq 2$; see Table 1 for the exact statements).

\section{Study outcomes}

Sociodemographic and health characteristics included age, gender, body mass index (BMI), current smoking status, and years since COPD diagnosis. The NHWS asks respondents to indicate the conditions they have been diagnosed with from a list of conditions, and these were used to calculate

Table I Dyspnea measurement used in GOLD guidelines and the current study

\begin{tabular}{lll}
\hline $\begin{array}{l}\text { GOLD } \\
\text { classification }\end{array}$ & mMRC wording & Current study wording \\
\hline Less symptoms & 0: I only get breathless with strenuous exercise & I only get breathless after strenuous exercise \\
& I get breathless after moderate exercise & Lower dyspnea \\
& $\begin{array}{l}\text { ground or walking up a slight hill } \\
\text { 2: On level ground, I walk slower than people of } \\
\text { the same age because of breathlessness, or have } \\
\text { to stop for breath when walking at my own pace }\end{array}$ & $\begin{array}{l}\text { I get breathless when hurrying on level } \\
\text { I walk slower than most people my age due } \\
\text { to my breathing }\end{array}$ \\
& $\begin{array}{l}\text { I: I stop for breath after walking about I00 yards have to stop for breath even } \\
\text { or after a few minutes on level ground } \\
4: \text { I am too breathless to leave the house or I am } \\
\text { breathless when dressing }\end{array}$ & $\begin{array}{l}\text { I stop for breath every few minutes while } \\
\text { walking, even on level ground } \\
\text { I am too breathless to leave the house }\end{array}$ \\
& & \\
\hline
\end{tabular}

Note: ${ }^{a} \mathrm{mMRC}$ scale is used with the permission of the Medical Research Council.

Abbreviations: GOLD, Global Initiative for Chronic Obstructive Lung Disease; mMRC, modified Medical Research Council. 
the Charlson Comorbidity Index (CCI). ${ }^{32}$ Health status of respondents was assessed through the revised Short Form-36 health questionnaire (SF-36)v2. ${ }^{33}$ This instrument is designed to report on eight health concepts (physical functioning, role physical, bodily pain, general health, vitality, social functioning, role emotional, and mental health). Two summary scores were also calculated: physical component summary (PCS) and mental component summary (MCS) scores. The current study used the standard norm-based scores for both the individual health concept scores and the two-component summary scores as calculated by the scoring software provided by the scale developer. These scores have a mean of 50 and a standard deviation (SD) of 10 for the US population (no pan-European norms are available for scoring, and scores based on the US norms are commonly presented regardless of country) ${ }^{33}$ Higher scores indicate better HRQoL. The SF-6D preference-based health utility was also calculated from the responses to the SF-36v2 using UK general population values. ${ }^{34}$ The SF-6D index has interval scoring properties and yields summary scores on a theoretical scale of $0-1$, with 1 indicating full health.

Impairment in work and non-work daily activities due to health in the past 7 days was assessed using the General Health version of the Work Productivity and Activity Impairment questionnaire. ${ }^{35}$ Employed respondents provided data for absenteeism (percentage of work time missed), presenteeism (percentage of impairment while at work), and overall work productivity loss (an estimate that combines absenteeism and presenteeism). All respondents indicated their level of activity impairment (percentage of impairment in daily activities because of health; this refers to non-work activities and does not specifically refer to physical activity).

Health care resource use was captured by the number of health care provider (HCP) visits, emergency room (ER) visits, and hospitalizations in 6 months prior to the survey.

\section{Analyses}

Lower and higher dyspnea groups were compared on sociodemographic characteristics, general health characteristics, length of COPD diagnosis, and outcomes by using an independent sample $t$-test for continuous variables and the chi-square test for categorical variables.

Subsequently, a series of regression analyses were conducted to compare the outcomes of the two dyspnea groups while adjusting for covariates. Covariates included country, age (as a continuous variable), gender, marital status (married or living with partner vs not married), completion of a university degree (yes or no), employment status (full-time, part-time, or self-employed vs unemployed), household income (median split within country), BMI category (underweight, normal weight, overweight, obese, or decline to answer), smoking (current smoker, former smoker, or never smoked cigarettes), alcohol use (any vs none), exercise (selfreported as the number of days in the past month with vigorous exercise for $\geq 20$ minutes; coarsened to $0 \mathrm{vs} \geq 1$ day), CCI (continuous), and length of COPD diagnosis (continuous).

Linear models were used for HRQoL outcomes, and generalized linear models with a negative binomial distribution and a log-link function were used for outcomes that were not normally distributed, including work and activity impairment as well as health care resource use.

\section{Results}

A total of 768 respondents met the inclusion criteria, of whom $245(32 \%)$ were categorized in the higher dyspnea group. Those in the higher dyspnea group were less likely to be employed ( $P=0.004)$, more likely to be obese (BMI $\left.\geq 30 \mathrm{~kg} / \mathrm{m}^{2} ; P=0.005\right)$, less likely to have exercised in the previous month $(P<0.001)$, and had slightly higher CCI scores $(P=0.012)$ relative to the respondents with lower dyspnea (Table 2).

HRQoL was worse among patients with higher dyspnea than among those with lower dyspnea (Figure 1A). Every domain and summary score calculated from the SF-36v2 was lower in patients with higher dyspnea (all $P<0.001$ ). The mean PCS score was 8.4 points lower and the mean MCS score was 4.1 points lower in patients with higher dyspnea. The mean health utility score was lower by 0.07 points in patients with higher dyspnea.

No significant differences in work impairment were observed between patients with higher and lower dyspnea (Table 3). Higher dyspnea was associated with a significantly greater mean impairment in (non-work) daily activities (65\% vs $42 \%, P<0.001)$. The difference in the number of HCP visits did not reach significance $(P=0.08)$. No statistically significant difference was observed in ER visits or hospitalizations.

\section{Multivariable results}

There were statistically significant decrements in all eight domains of the SF-36 health profile in the patients with higher dyspnea after adjustment for sociodemographics, general health characteristics, and length of COPD (Figure 1B). Adjusted differences between groups ranged from 3.9 points for mental health to 8.2 points for the physical functioning subscale. The adjusted mean PCS score was lower by 
Table 2 Characteristics of respondents according to the level of dyspnea

\begin{tabular}{|c|c|c|c|}
\hline Variables & Lower dyspnea $(n=523)$ & Higher dyspnea $(n=245)$ & $P$-value \\
\hline \multicolumn{4}{|l|}{ Country (\%) } \\
\hline France & 13.8 & 14.3 & 0.206 \\
\hline Germany & 38.0 & 32.2 & \\
\hline UK & 21.6 & 27.3 & \\
\hline Italy & 13.4 & 15.9 & \\
\hline Spain & 13.2 & 10.2 & \\
\hline Age in years, mean (SD) & $61.39(9.78)$ & $62.65(9.03)$ & 0.089 \\
\hline Female (\%) & 41.1 & 42.4 & 0.725 \\
\hline Married/living with partner (\%) & 67.5 & 58.0 & 0.010 \\
\hline University degree (\%) & 30.2 & 24.5 & 0.101 \\
\hline Employed (\%) & 34.4 & 24.1 & 0.004 \\
\hline \multicolumn{4}{|l|}{ Household income (\%) } \\
\hline Below median & 61.4 & 63.7 & 0.828 \\
\hline Above median & 29.6 & 27.8 & \\
\hline Decline to answer & 9.0 & 8.6 & \\
\hline \multicolumn{4}{|l|}{ BMI categories (\%) } \\
\hline Underweight $\left(<18.5 \mathrm{~kg} / \mathrm{m}^{2}\right)$ & 2.9 & 1.6 & 0.005 \\
\hline Normal $\left(18.5\right.$ to $\left.<25 \mathrm{~kg} / \mathrm{m}^{2}\right)$ & 33.7 & 28.6 & \\
\hline Overweight ( 25 to $<30 \mathrm{~kg} / \mathrm{m}^{2}$ ) & 38.8 & 31.8 & \\
\hline Obese $\left(\geq 30 \mathrm{~kg} / \mathrm{m}^{2}\right)$ & 23.9 & 36.3 & \\
\hline Decline to answer & 0.8 & 1.6 & \\
\hline \multicolumn{4}{|l|}{ Smoking status (\%) } \\
\hline Current & 40.0 & 34.3 & 0.016 \\
\hline Former & 41.5 & 52.2 & \\
\hline Never & 18.5 & 13.5 & \\
\hline Drinks alcohol (\%) & 72.5 & 68.6 & 0.266 \\
\hline Exercise in past 30 days (\%) & 46.5 & 30.6 & $<0.001$ \\
\hline $\mathrm{CCl}$, mean (SD) & $1.76(1.26)$ & $2.03(I .7 I)$ & 0.012 \\
\hline Length of diagnosis in years, mean (SD) & $10.28(11.80)$ & II.58 (I I.84) & 0.158 \\
\hline
\end{tabular}

Note: $P$-value is calculated from the independent-samples $t$-test for the difference between means and from the chi-square test for the differences in proportion.

Abbreviations: $\mathrm{BMI}$, body mass index; $\mathrm{CCl}$, Charlson comorbidity index; SD, standard deviation.

6.9 points, whereas the adjusted mean MCS score was lower by 3.5 points. After adjustment, SF-6D health utilities were 0.06 points lower in higher dyspnea patients than in lower dyspnea patients.

Activity impairment was considerably greater among patients with higher dyspnea after adjustment $(P<0.001)$. Consistent with the unadjusted results, differences in regression-adjusted work impairment did not reach statistical significance (all $P>0.05$; Table 4 ). Total HCP visits and hospitalizations did not differ according to the level of dyspnea in unadjusted comparisons, although regression indicated an association of greater dyspnea with more self-reported ER visits $(P<0.05)$.

\section{Discussion}

In the current study, approximately one in three patients currently using a prescription medication for COPD reported levels of dyspnea consistent with symptomatic COPD according to GOLD strategy ( $\mathrm{mMRC} \geq 2$ ). More severe self-reported dyspnea was associated with significant impairments in general HRQoL and work productivity, and these decrements in HRQoL exceeded the 5-point threshold generally considered as the minimally important difference (MID) for general health, physical functioning, role emotional, role physical, and social functioning components of the 8-factor health profile. In addition, both the MCS and PCS scores exceeded the MID of 3 points, with adjusted difference in PCS score being more than twice the MID. ${ }^{33}$ Impairment in daily activities was also markedly greater among patients with higher dyspnea, by $18 \%$ in absolute terms, and nearly $50 \%$ in relative terms. Finally, those with higher dyspnea also reported higher rates of ER visits compared to those with lower dyspnea after adjustment for covariates.

The proportion of patients with significant dyspnea observed in this study is comparable or slightly lower than that in the European countries included in the Continuing to Confront COPD survey. ${ }^{36}$ This survey included respondents not using a prescription for COPD and did not exclude 

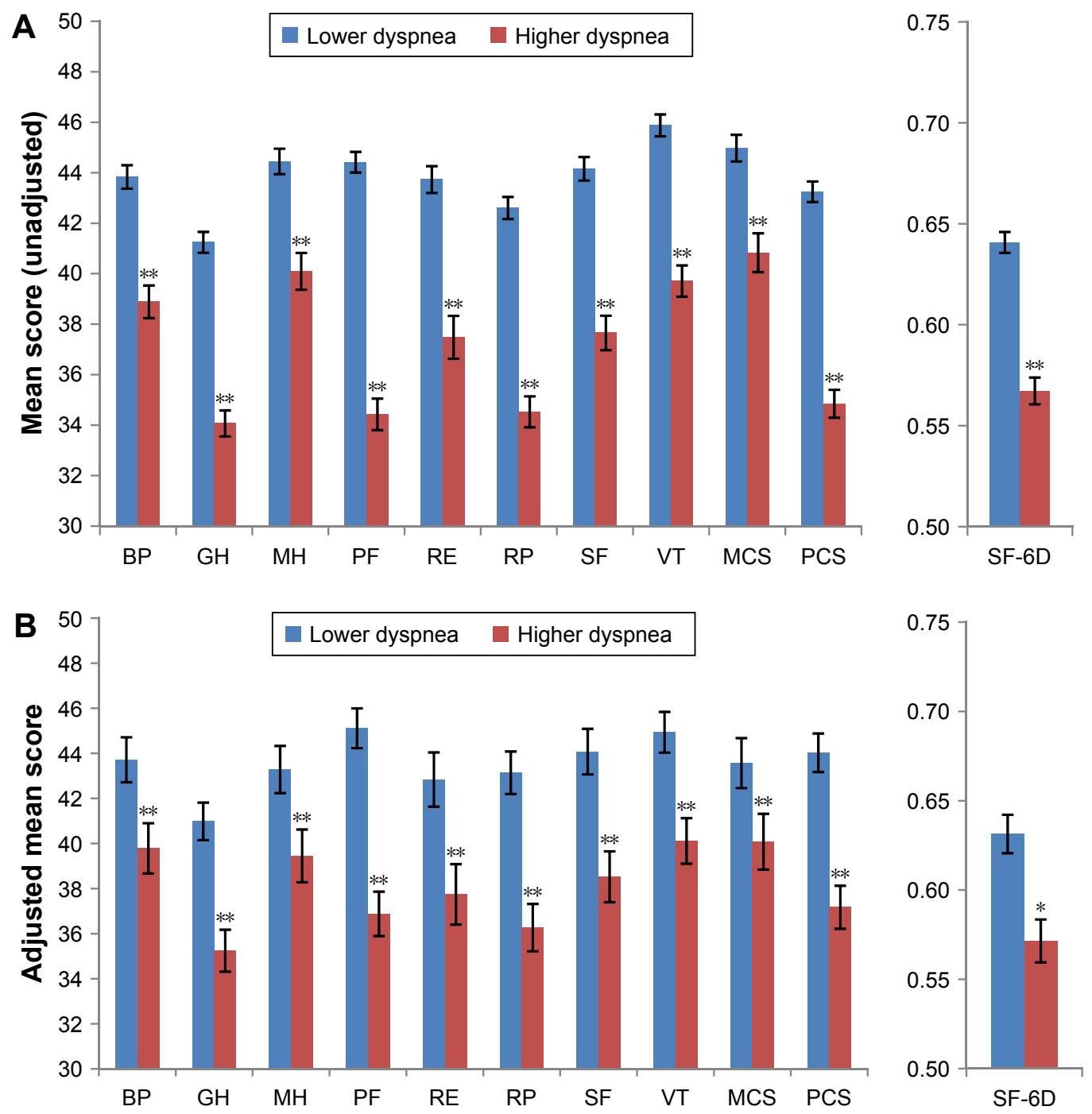

Figure I (A) Functional health status and health utility scores by the level of dyspnea (unadjusted). (B) Functional health status and health utility by the level of dyspnea after regression adjustment.

Notes: $* P<0.01 ; * * P<0.001$.

Abbreviations: BP, bodily pain; GH, general health; MCS, mental component summary; MH, mental health; PCS, physical component summary; PF, physical functioning; RE, role emotional; RP, role physical; SF, social functioning; SF-6D, Short Form-6D health utility; VT, vitality.

Table 3 Work impairment and health care use by the level of dyspnea

\begin{tabular}{|c|c|c|c|}
\hline & Lower dyspnea $(n=523)$ & Higher dyspnea $(n=245)$ & $P$-value \\
\hline & Mean (SD) & Mean (SD) & \\
\hline \multicolumn{4}{|l|}{ Work impairment, \% ( $\mathrm{N}=\mathrm{L}$ and $\mathrm{H}$ dyspnena) } \\
\hline Absenteeism (I78 and 58) & I $2.5(26.5)$ & $13.9(26.1)$ & 0.732 \\
\hline Presenteeism (168 and 56) & $31.9(29.6)$ & $38.0(27.9)$ & 0.170 \\
\hline Overall work impairment (I78 and 58) & $37.7(34.1)$ & $43.7(32.8)$ & 0.240 \\
\hline Activity impairment (\%) & $42.3(31.3)$ & $64.8(27.1)$ & $<0.001$ \\
\hline \multicolumn{4}{|l|}{ Health care use (prior to 6 months) } \\
\hline HCP visits & $9.0(8.4 I)$ & $10.20(9.52)$ & 0.082 \\
\hline ER visits & $0.39(1.57)$ & $0.50(1.33)$ & 0.326 \\
\hline Hospitalizations & $0.27(0.68)$ & $0.36(0.84)$ & 0.112 \\
\hline
\end{tabular}

Abbreviations: ER, emergency room; H, higher; HCP, health care provider; L, lower; SD, standard deviation. 
Table 4 Regression-adjusted impairment and health care use by the level of dyspnea

\begin{tabular}{|c|c|c|c|c|c|}
\hline & \multicolumn{2}{|c|}{ Lower dyspnea $(n=523)$} & \multicolumn{2}{|c|}{ Higher dyspnea (n=245) } & \multirow[t]{2}{*}{$P$-value } \\
\hline & Mean & SE & Mean & SE & \\
\hline \multicolumn{6}{|l|}{ Work impairment } \\
\hline Absenteeism (\%) & 6.1 & 3.0 & 7.9 & 4.7 & 0.562 \\
\hline Presenteeism (\%) & 25.5 & 5.2 & 35.0 & 8.1 & 0.055 \\
\hline Overall work impairment (\%) & 31.6 & 6.3 & 40.3 & 9.0 & 0.118 \\
\hline Activity impairment (\%) & 36.8 & 2.5 & 54.7 & 4.2 & $<0.001$ \\
\hline \multicolumn{6}{|l|}{ Health care use (prior to 6 months) } \\
\hline HCP visits & 8.0 & 0.7 & 8.4 & 0.9 & 0.438 \\
\hline ER visits & 0.40 & 0.09 & 0.61 & 0.16 & 0.030 \\
\hline Hospitalizations & 0.00 & 0.00 & 0.00 & 0.00 & 0.538 \\
\hline
\end{tabular}

Abbreviations: ER, emergency room; HCP, health care provider; SE, standard error of the mean.

individuals with comorbid asthma, suggesting that it could have included some individuals whose dyspnea would have been resolved with medication or may be attributable to asthma. These new data suggest that the high rate of dyspnea among COPD patients is present despite treatment and is not attributable to asthma.

Our findings also provide further confirmation of the relationship between dyspnea and HRQoL. A recent study has shown that dyspnea can be a strong predictor of mental and physical outcome components of HRQoL, even more so than the objective measures of lung functioning. ${ }^{37}$ Indeed, a meta-analysis of the correlation between factors associated with disease-specific HRQoL as measured by the St George's Respiratory Questionnaire among COPD patients indicated dyspnea as one of the key correlates of HRQoL, ${ }^{38}$ and the general relationship between dyspnea and HRQoL has been demonstrated in a variety of studies ranging from longitudinal studies incorporating interviewer-administered scales ${ }^{39}$ as well as the mMRC and other self-report scales. ${ }^{25,40-42} \mathrm{~A}$ particular contribution of the current study is the assessment of the relationship between dyspnea and the full 8 -factor health profile of the SF-36v2, in addition to the more commonly reported summary measures derived from the instrument. The generic, rather than disease-specific, nature of the SF-36v2 also provides measures that can be compared across conditions, providing context to the nature and extent of the impairment relative to other diseases.

The demographic characteristics of patients with COPD did not differ markedly based on severity of dyspnea, although individuals who reported higher levels of dyspnea tended to be more often obese and were less likely to be currently employed. As such, the decrements in outcomes associated with dyspnea observed in the unadjusted comparisons are not likely to be due to group differences in personal characteristics. The groups continued to differ after adjustments for a broad range of sociodemographic and health characteristics, including BMI, comorbid medical conditions, and exercise, but as weight gain and lack of exercise may actually be the result of lower levels of physical activity due to dyspnea, the adjusted comparisons may be overly conservative.

\section{Limitations}

While the current study provides important insight into the experience of COPD sufferers in Europe using a large-scale representative survey, it is important to note the study limitations. The cross-sectional design of this study did not allow for causal attributions, although it seems much more likely that dyspnea is responsible for the decrements in HRQoL than vice versa, and the relationship between dyspnea and HRQoL remained after controlling for covariates. Likewise, previous longitudinal research suggests dyspnea leads to lower HRQoL across multiple domains. ${ }^{39}$ Furthermore, the survey methodology employed did not enable patients' diagnosis of COPD to be confirmed, nor was information on patients' treatment history or objective measures of lung functioning available. It is also possible that some of the dyspnea experienced by patients is attributable to conditions other than COPD, such as congestive heart failure, though congestive heart failure was reported by a small minority of the respondents ( $11 \%$ and $4 \%$ of those with and without dyspnea, respectively; data not presented) and was included in the regression analysis through the CCI. These limitations, as well as the possible recall bias among the study participants, suggest caution in drawing firm conclusions.

\section{Conclusion}

The findings of this study highlight the need for a complete assessment of dyspnea in patients with COPD. This is important, as this symptom is associated with notable impairments in the patients' ability to function across a multitude of 
HRQoL domains. This is especially important in the context of patients with COPD because, many European patients in the current study continued to experience dyspnea despite being treated with a prescription medication for it. The results of this study suggest that many patients experience higher levels of dyspnea despite treatment and that additional therapies and/or more intense treatment regimens should be considered.

\section{Acknowledgments}

Writing and editorial support was provided by Errol Phillip, $\mathrm{PhD}$, funded by Kantar Health, and Vishal Yadav (employee of Novartis).

\section{Disclosure}

Novartis paid fees to Kantar Health for access to survey data, analysis, and reporting. Jean-Bernard Gruenberger and Dorothy Keininger are employees of Novartis. Jeffrey Vietri is an employee of Kantar Health. Donald A Mahler has received consulting fees for advisory boards from Boehringer Ingelheim, GlaxoSmithKline (GSK), Novartis, Sunovion, and Theravance and is on Speaker's Bureaus of Boehringer Ingelheim, GSK, and Sunovion. The authors report no other conflicts of interest in this work.

\section{References}

1. Joshi M, Joshi A, Bartter T. Symptom burden in chronic obstructive pulmonary disease and cancer. Curr Opin Pulm Med. 2012;18(2): 97-103.

2. Ferrer M, Alonso J, Morera J, et al. Chronic obstructive pulmonary disease stage and health-related quality of life. Ann Intern Med. 1997;127(12): 1072-1079.

3. Ståhl E, Lindberg A, Jansson S-A, et al. Health-related quality of life is related to COPD disease severity. Health Qual Life Outcomes. 2005;3:56

4. Stahl E, Wadbo M, Bengtsson T, Strom K, Lofdahl C-G. Health-related quality of life, symptoms, exercise capacity and lung function during treatment for moderate to severe COPD. J DRUG Assess. 2002;5(1): 81-94.

5. Miravitlles M, Alvarez-Sala JL, Lamarca R, et al; IMPAC Study Group. Treatment and quality of life in patients with chronic obstructive pulmonary disease. Qual Life Res. 2002;11(4):329-338.

6. Jones PW. Activity limitation and quality of life in COPD. COPD. 2007; 4(3):273-278.

7. Faulkner MA, Hilleman DE. The economic impact of chronic obstructive pulmonary disease. Expert Opin Pharmacother. 2002;3(3):219-228.

8. Darkow T, Kadlubek PJ, Shah H, Phillips AL, Marton JP. A retrospective analysis of disability and its related costs among employees with chronic obstructive pulmonary disease. J Occup Environ Med. 2007; 49(1):22-30.

9. Sin DD, Stafinski T, Ng YC, Bell NR, Jacobs P. The impact of chronic obstructive pulmonary disease on work loss in the United States. Am J Respir Crit Care Med. 2002;165(5):704-707.

10. Jones PW, Bosh TK. Quality of life changes in COPD patients treated with salmeterol. Am J Respir Crit Care Med. 1997;155(4):1283-1289.

11. Tonnel A, Perez T, Grosbois J, et al. Effect of tiotropium on healthrelated quality of life as a primary efficacy endpoint in COPD. Int $J$ Chron Obstruct Pulmon Dis. 2008;3(2):301-310.
12. Brusasco V, Hodder R, Miravitlles M, Korducki L, Towse L, Kesten S Health outcomes following treatment for 6 months with once daily tiotropium compared with twice daily salmeterol in patients with COPD. Thorax. 2006;58(5):399-404.

13. Toy EL, Beaulieu NU, Mchale JM, et al. Treatment of COPD: relationships between daily dosing frequency, adherence, resource use, and costs. Respir Med. 2011;105(3):435-441.

14. Mahler DA, Kerwin E, Ayers T, et al. FLIGHT1 and FLIGHT2: efficacy and safety of QVA149 (indacaterol/glycopyrrolate) versus its monocomponents and placebo in patients with chronic obstructive pulmonary disease. Am J Respir Crit Care Med. 2015;192(9):1068-1079.

15. Kornmann O, Dahl R, Centanni S, et al; NLIGHT-2 (Indacaterol Efficacy Evaluation Using 150- $\mu$ g Doses with COPD Patients) study investigators. Once-daily indacaterol versus twice-daily salmeterol for COPD: a placebo-controlled comparison. Eur Respir J. 2011;37(2): 273-279.

16. Kerwin E, Hebert J, Gallagher N, et al. Efficacy and safety of NVA237 versus placebo and tiotropium in patients with COPD: the GLOW2 study. Eur Respir J. 2012;40(5):1106-1114

17. Donohue JF, Fogarty C, Lotvall J, et al; INHANCE Study Investigators Once-daily bronchodilators for chronic obstructive pulmonary disease: indacaterol versus tiotropium. Am J Respir Crit Care Med. 2010; 182(2):155-162.

18. Price D, West D, Brusselle G, et al. Management of COPD in the UK primary-care setting: an analysis of real-life prescribing patterns. Int $J$ Chron Obstruct Pulmon Dis. 2014;9:889-904.

19. Dransfield MT, Bailey W, Crater G, Emmett A, O’Dell DM, Yawn B. Disease severity and symptoms among patients receiving monotherapy for COPD. Prim Care Respir J. 2011;20(1):46-53.

20. Ehteshami-Afshar S, FitzGerald JM, Doyle-Waters MM, Sadatsafavi M. The global economic burden of asthma and chronic obstructive pulmonary disease. Int J Tuberc Lung Dis. 2016;20(1):11-23.

21. Burney PGJ, Patel J, Newson R, Minelli C, Naghavi M. Global and regional trends in COPD mortality, 1990-2010. Eur Respir J. 2015;45(5): 1239-1247.

22. European Respiratory Society. The European Lung White Book. Sheffield, UK: European Respiratory Society Publications Office; 2013.

23. Parshall MB, Schwartzstein RM, Adams L, et al. An official American thoracic society statement: update on the mechanisms, assessment, and management of dyspnea. Am J Respir Crit Care Med. 2012;185(4): 435-452.

24. Roche N, Chavannes NH, Miravitlles M. COPD symptoms in the morning: impact, evaluation and management. Respir Res. 2013;14:112.

25. Demir G, Akkoca O, Dogan R, Saryal S, Karabiyikoglu G. [The evaluation of dyspnea and quality of life in COPD]. Tuberk Toraks. 2003;51(4):365-372. Indonesian.

26. Elias Hernandez MT, Ortega Ruiz F, Sanchez Riera H, et al. Papel de la disnea en la calidad de vida del paciente con enfermedad pulmonar obstructiva crónica [Role of dyspnea in quality of life of the patient with chronic obstructive pulmonary disease]. Arch Bronconeumol. 1999; 35(6):261-266. Spanish.

27. Ries AL. Impact of chronic obstructive pulmonary disease on quality of life: the role of dyspnea. Am J Med. 2006;119(10 Suppl 1):12-20.

28. Jones PW, Harding G, Berry P, Wiklund I, Chen W-H, Kline Leidy N. Development and first validation of the COPD assessment test. Eur Respir J. 2009;34(3):648-654.

29. Brooks SM. Surveillance for respiratory hazards. ATS News. 1982; $8: 12-16$.

30. Bestall JC, Paul EA, Garrod R, Garnham R, Jones PW, Wedzicha JA. Usefulness of the Medical Research Council (MRC) dyspnoea scale as a measure of disability in patients with chronic obstructive pulmonary disease. Thorax. 1999;54(7):581-586.

31. Jones PW. COPD assessment test - rationale, development, validation and performance. COPD. 2013;10(2):269-271.

32. Charlson ME, Pompei P, Ales KL, MacKenzie CR. A new method of classifying prognostic comorbidity in longitudinal studies: development and validation. J Chronic Dis. 1987;40(5):373-383. 
33. Maruish ME, Editor. NEW SF36v2 User Guide. 3rd Ed. Lincoln, RI: Quality Metric; 2011.

34. Brazier JE, Roberts J. The estimation of a preference-based measure of health from the SF-12. Med Care. 2004;42(9):851-859.

35. Reilly MC, Zbrozek AS, Dukes EM. The validity and reproducibility of a work productivity and activity impairment instrument. Pharmacoeconomics. 1993;4(5):353-365.

36. Landis SH, Muellerova H, Mannino DM, et al. Continuing to confront COPD international patient survey: methods, COPD prevalence, and disease burden in 2012-2013. Int J COPD. 2014;9:597-607.

37. Justine M, Tahirah F, Mohan V. Health-related quality of life, lung function and dyspnea rating in COPD patients. Monaldi Arch Chest Dis. 2013;79(3-4):116-120.

38. Tsiligianni I, Kocks J, Tzanakis N, Siafakas N, van der Molen T. Factors that influence disease-specific quality of life or health status in patients with COPD: a systematic review and meta-analysis of Pearson correlations. Prim Care Respir J. 2011;20(3):257-268.
39. Mahler DA, Tomlinson D, Olmstead EM, Tosteson AN, O'Connor GT. Changes in dyspnea, health status, and lung function in chronic airway disease. Am J Respir Crit Care Med. 1995;151(1):61-65.

40. Jones PW, Adamek L, Nadeau G, Banik N. Comparisons of health status scores with MRC grades in COPD: implications for the GOLD 2011 classification. Eur Respir J. 2013;42(3):647-654.

41. Lin F-J, Pickard AS, Krishnan JA, et al. Measuring health-related quality of life in chronic obstructive pulmonary disease: properties of the EQ-5D-5L and PROMIS-43 short form. BMC Med Res Methodol. 2014; $14: 78$.

42. Akinci AC, Pinar R, Demir T. The relation of the subjective dyspnoea perception with objective dyspnoea indicators, quality of life and functional capacity in patients with COPD. J Clin Nurs. 2013;22(7-8):969-976.

\section{Publish your work in this journal}

The International Journal of COPD is an international, peer-reviewed journal of therapeutics and pharmacology focusing on concise rapid reporting of clinical studies and reviews in COPD. Special focus is given to the pathophysiological processes underlying the disease, intervention programs, patient focused education, and self management protocols.

\section{Dovepress}

This journal is indexed on PubMed Central, MedLine and CAS. The manuscript management system is completely online and includes a very quick and fair peer-review system, which is all easy to use. Visit http://www.dovepress.com/testimonials.php to read real quotes from published authors.

Submit your manuscript here: http://www.dovepress.com/international-journal-of-chronic-obstructive-pulmonary-disease-journal 